\title{
Help in handling cells, spills and refills
}

Free trials for Finnpipettes, a gauge for cell aggregation and kits for chemical clean-ups round out this week's page. There are novel approaches to all kinds of laboratory needs.

A Petri dish press from World Products Instruments stamps plates with a grid that makes microscopic navigation easier (Reader Service No. 10(0). The BB Press will mark ordinary $35 \mathrm{~mm}$ plastic dishes

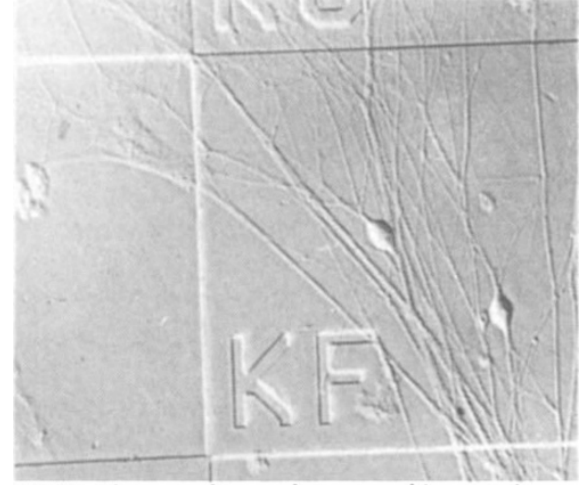

WPI's plate marker makes a good impression.

with a grid composed of $26 \times 26$ squares measuring $300 \mu \mathrm{m}$ on a side. Each square carries a row-and-column identifier to facilitate locating areas under the microscope. The entire grid measures $8 \mathrm{~mm}$ on one side, and WPI says the heat-stamping procedure takes less than $2 \mathrm{~min}$. The company's $\$ 495$ (US) press uses a die etched on a silicon wafer and mounted in a steel tool assembly to make its impressions.

NMR doesn't have to be an in-house job anymore. Spectral Data Services in Champaign, IL has a commercial highfield NMR service that includes data acquisition, interpretation and experimental design (Reader Service No. 101). SDS charges $\$ 35$ to $\$ 50$ (US) per hour to perform a variety of analyses on its 360 and $270 \mathrm{MHz}$ Oxford-Nicolet systems. The company also provides consultation and simulations.

Both the physical forces and the biological interactions that influence cell-surface adhesion can be measured with LH Fermentation's CAMM (Reader Service No. 102). Developed by $\mathrm{H}$ W Fowler at the University of Bath, the Cell Adhesion Measurement Module houses a radial flow chamber that gauges adhesion by attachment in the presence of shear forces, and biological interactions by forcing cell detachment. The chamber can be autoclaved. A control unit completes the CAMM, which LH sells for about $£ 3,000$ (UK).

These notes are compiled by Karen Wright from information provided by the manufacturers. To obtain further details about these products, use the reader service card bound inside the journal. Prices quoted are sometimes nominal and apply only within the country indicated.

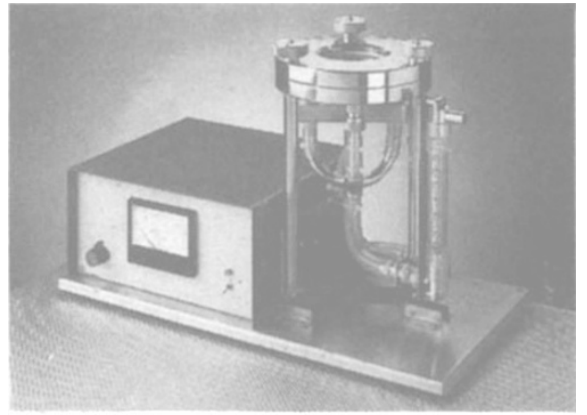

The CAMM: perfect for sticky situations.

Safer spills are the object of a chemical spill centre from Helapet in Hertfordshire (Reader Service No. 103). Available at the end of October, the $\$ 295$ (UK) centre is equipped with protective gear for both operators and bench surfaces and supplies chemical hazard disposal bags.

One month with a digital Finnpipette for free: that is the promise from Labsystems, who offers the pipettes in volumes ranging from $0.5 \mu \mathrm{l}$ to $5 \mathrm{ml}$ (Reader Servi-

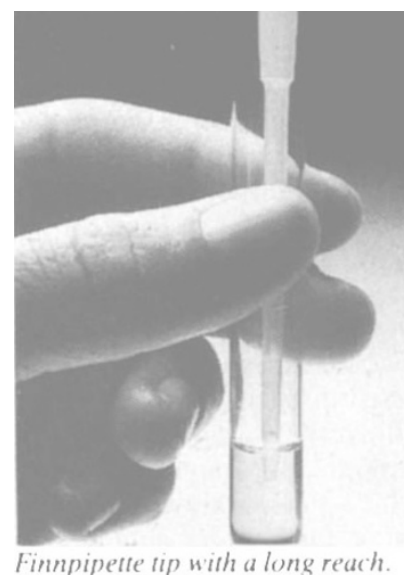

A Fimnipette tip with a long reach.

ce No. 104). The company will also throw in a "generous supply" of disposable tips. Currently Labsystems is also promoting its Finntip 60 Extended tip pipette which fits most pipettes with volumes of $5 \mu \mathrm{l}$, to $200 \mu \mathrm{l}$, and can serve as a syringe reservoir for some stopper pipettes.

Clandon Scientific has just begun selling a platelet aggregation recorder that can monitor up to four channels simultaneously (Reader Service No. 105). The Aggrecorder II, a product of Kyoto Daiichi Kagaku in Japan, has a 7-inch CRT monitor and a four-colour graphic plotter for visualizing results. Priced under $£ 9,000$ (UK). Clandon's instrument uses straightforward calibration procedures and error comments.

Dynatech has just come out with another alternative in microtitre plate design (Reader Service No. 106). The new Duo-Strip system consists of 16-well units moulded as two rows of 8 wells each. The strips are available in irradiated versions and $U$ and flat-bottom formats.

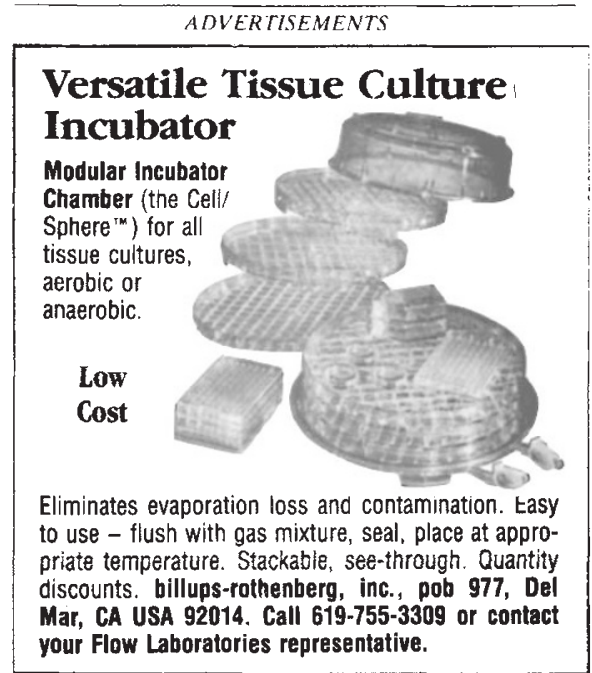

your Flow Laboratories representative.

Reader Service No.7
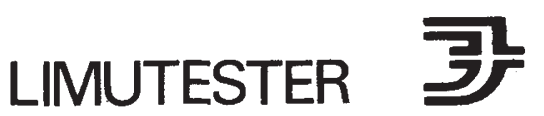

(gelation-capillary method)

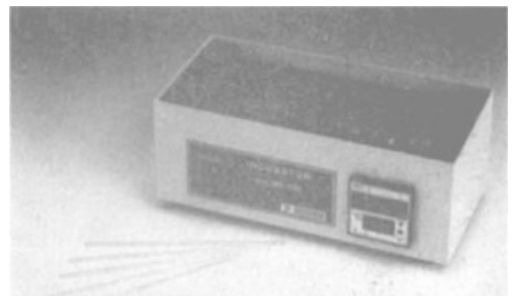

Precise Detection of Endotoxins

This LIMUTESTER detects Endotoxins promptly, applying to gelation reaction of LAL and a glass capillary.

The LIMUTESTER is simple, economical and usable anywhere, especially needs no endotoxin-free laboratory glass wares.

LIMUTESTER INCUBATOR is available.

FUNAKOSHI PHARMACEUTICAL CO., LTD.

Science Business Div. Research Material Sect.

2-3 Surugadai, Kanda, Chiyoda-ku, Tokyo, Japan

Telephone: Tokyo 03-293-2352

Telefax : 81-3-295-5545

Telex 